\title{
AIR-VOID-AFFECTED ZONE IN CONCRETE BEAM UNDER FOUR-POINT BENDING FRACTURE
}

\author{
Chuanchuan ZHANG ${ }^{1}$, Xinhua YANG ${ }^{1,2}, \mathrm{Hu} \mathrm{GAO}^{1}$ \\ ${ }^{1}$ School of Civil Engineering and Mechanics, Huazhong University of Science and Technology, \\ Wuhan 430074, China \\ ${ }^{2}$ Hubei Key Laboratory of Engineering Structural Analysis and Safety Assessment, \\ 1037 Luoyu Road, 430074 Wuhan, China
}

Received 16 November 2017; accepted 15 February 2018

\begin{abstract}
A series of numerical simulations were performed on prenotched four-point bending (FPB) concrete beams containing air voids of different sizes and locations by using the finite element method combined with the cohesive crack model. The void-affected zone was proposed for characterizing the effect of a void on a fracture, and its size was determined by moving an air void horizontally until the crack path changed. As a function of air void location and size, the dimensionless affected-zone radius was fitted according to the numerical results. Finally, the fracture processes of the prenotched FPB concrete beams with randomly distributed voids were simulated numerically, and the affected-zone radius was used to explain the choice of crack paths to verify the prediction. It was found that the prediction is accurate for an isolated affected zone and is roughly approximate for an overlapped one.
\end{abstract}

Keywords: concrete, air void, fracture, affected-zone, cohesive model, four-point bending.

\section{Introduction}

As a building material, concrete has been widely used in civil engineering, hydraulic engineering, and other infrastructure construction. It is made of cement, water, sand, and coarse aggregates, and therefore, it usually contains natural defects such as micro-cracks, weak interfaces, and air voids (Garbacz et al. 2017; Qin et al. 2016; Ren et al. 2015; Xie et al. 2015). Defects have complicated effects. On the one hand, they can directly weaken material properties so that the performance indicators of concrete such as permeability, durability, and fracture resistance are usually lower than their design values. On the other hand, a crack trajectory is possibly deflected from rectilinearity owing to interactions between a crack and defects. The crack path deflection can be linked to an increase in material toughness by dissipating more fracture energy (Misseroni et al. 2015). It is very useful for the design purposes of concrete structures to clarify effects of defects on crack propagation in concrete.

In recent years, air voids in concrete material and construction have attracted significant attention. Some nondestructive testing equipment, such as scanning electron microscopes and X-ray computed tomography, combined with the image analysis (IA) technique and ultrasonic scattering (US) technique, was used for air void detection. Using the IA technique, Nambiar and Ramamurthy (2007) analyzed the size distribution, shape parameter, and spacing factor of air voids in concrete, and Mahoutian et al. (2015) examined the effect of powdered activated carbon in fly ash on the air void content and spacing factor of concrete. With the help of the US technique, Guo et al. (2016) measured the air void size distribution in hardened concrete, and Dong et al. (2016) successfully quantified air voids in concrete-filled steel tubes.

In addition, many studies were conducted on the effect of air voids on the performance of concrete by laboratory testing. The experiments proved that the volume fraction, size, and spacing of air voids all have significant influence on the strength and density of concrete (Nambiar, Ramamurthy 2007). Rehder et al. (2014) pointed out that an increase in pore size leads to a reduction in the fracture resistance of pervious concrete. Hu et al. (2016) found that initial air voids have a significant effect on the fatigue property of asphalt concrete. Nguyen et al. (2017) quantitatively analyzed the influences of air void porosity, distri-

*Corresponding author. E-mail: yangxinh@hust.edu.cn 


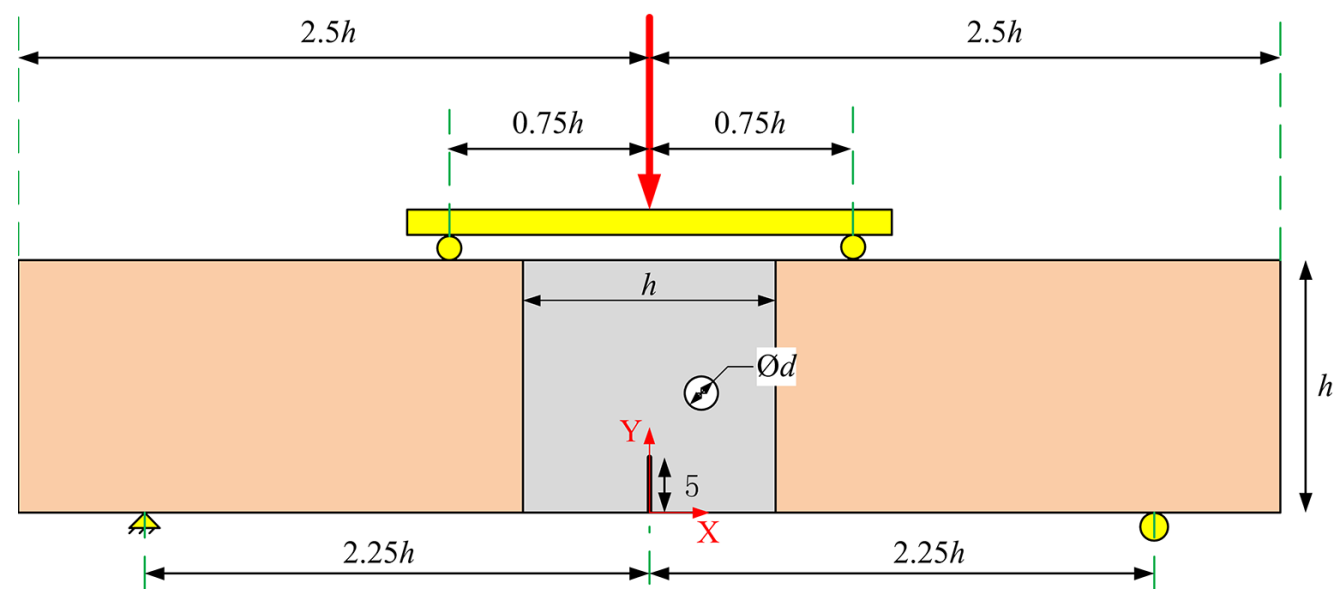

Figure 1. Prenotched FPB concrete beam

bution, and microstructure on the compressive behavior of concrete. However, owing to difficulties in controlling air void size and position, it is nearly impossible to assess the impact of air voids on concrete properties systematically by experiments.

Numerical simulation is a powerful investigation tool. Over the past several decades, computer performance has improved significantly, so that it became reality to simulate fracture behaviors of heterogeneous concrete at the mesoscale level. Many numerical methods, such as the digital image processing (DIP) method (Barbosa et al. 2011; Başyiğit et al. 2012) and the parameterization modeling (PM) method (Qin et al. 2013; Xu, Chen 2016; Yin et al. 2015; Zhang et al. 2016), were developed for modeling heterogeneous concrete with aggregates and mortar matrix. Recently, air voids were also contained in some numerical models created with the DIP (Huang et al. 2016) and PM (Ren, Sun 2017; Wang et al. 2015, 2016) methods to assess the effects of the characteristic parameters of air voids on the fracture properties of concrete. A cohesive crack model with a bilinear constitutive law, quadratic nominal stress cracking criterion, and linear damage evolution criterion was introduced to simulate the fracture processes (Yang et al. 2009; Yin et al. 2014).

As is well known, a crack would rather initiate and propagate in a weak zone. Accordingly, when a crack approaches an air void, it is probably attracted by the void, and changes its path. How does an air void affect crack propagation in concrete? How does a crack choose its path in concrete with a lot of randomly distributed voids? To answer these questions, the effects of air voids on fractures in concrete should be quantitatively studied. In this paper, a series of two-dimensional (2D) numerical simulations will be performed on a prenotched four-point bending (FPB) concrete beam with a single air void, and the effects of the void size and location on the fracture will be evaluated. Their fracture-affecting zones will be determined, and dimensionless zone sizes will be given as functions of air void size and location. Finally, this function will be used to explain the crack propagation in FPB multi-void concrete beams with randomly distributed voids.

\section{Numerical model}

As shown in Figure 1, a series of 2D concrete beam models with a height of $h$ and a length of $5 h$ are created. These models are subjected to a symmetrical FPB load. There is a distance of $4.5 h$ between the two supports, and a distance of $1.5 h$ between the two loading points. A crack with a depth of $5 \mathrm{~mm}$ and a width of $0.2 \mathrm{~mm}$ is located at the mid-span of the beam. In the center of the beam, a zone with a width of $h$ is considered. In this zone, an air void is arranged to measure its effect on the fracture. As shown in Figure 1, a rectangular coordinate system with the crack mouth as the origin, the beam bottom as the horizontal axis, and the axle wire as the vertical axis, is created. An air void with a diameter of $d$ has its center at a point of $(X, Y)$.

To simplify the calculations, the concrete beam is treated as a homogeneous material (Hassani, Hinton 1998; Ren et al. 2015). Both the triangular and quadrilateral plane stress solid elements are employed for discretization of the computation model. In order to simulate crack initiation and propagation, cohesive elements (Yin et al. 2012) are inserted in the central zone of the beam. Figure 2 exhibits the finite element mesh with red cohesive elements. The mesh is refined in the central zone. The material parameters are as follows (Dong et al. 2017). For the triangular

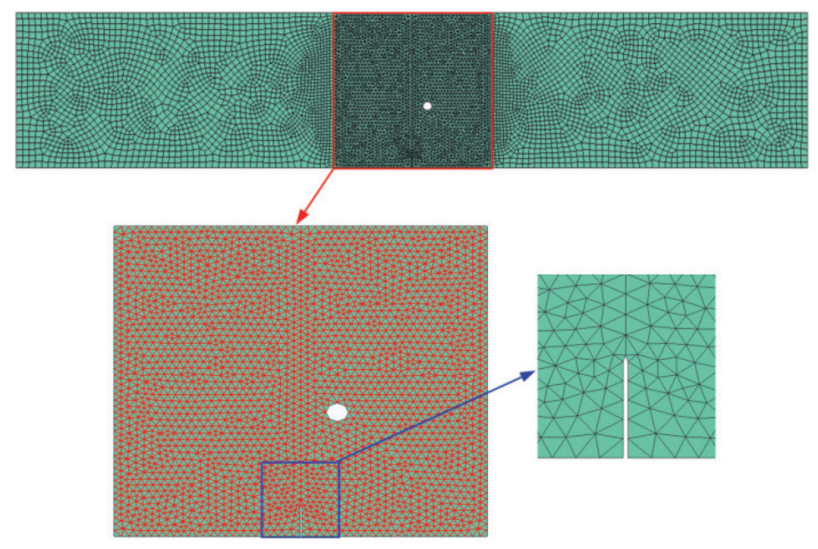

Figure 2. Finite element mesh with red cohesive elements 
Table 1. Number of nodes, numbers of elements, and computing time for different mesh densities

\begin{tabular}{|l|c|c|c|c|c|c|c|c|c|}
\hline \multicolumn{1}{|c|}{ Element size (mm) } & \multicolumn{3}{|c|}{1.00} & \multicolumn{3}{c|}{0.75} & \multicolumn{3}{c|}{0.50} \\
\hline \multicolumn{1}{|c|}{ Void size (mm) } & 1 & 3 & 5 & 1 & 3 & 5 & 1 & 3 & 5 \\
\hline Number of nodes & 21196 & 21043 & 20192 & 33472 & 32471 & 32387 & 69269 & 68046 & 67445 \\
Number of triangular elements & 5649 & 5496 & 5325 & 9407 & 9093 & 9065 & 20931 & 20547 & 20323 \\
Number of quadrilateral elements & 4172 & 4140 & 4140 & 5190 & 5131 & 5131 & 6449 & 6449 & 6449 \\
Number of cohesive elements & 8363 & 8076 & 7873 & 13967 & 13454 & 13438 & 31164 & 30655 & 30258 \\
Computing time (min) & 23 & 22 & 19 & 53 & 49 & 47 & 560 & 530 & 518 \\
\hline
\end{tabular}

and quadrilateral plane stress solid elements, the density is $2600 \mathrm{~kg} / \mathrm{m}^{3}$, Young's modulus is $28.0 \mathrm{GPa}$, and Poisson's ratio $v$ is 0.18 . For the cohesive elements, the elastic stiffness $k$ is $10^{6} \mathrm{MPa} / \mathrm{mm}$ (Wang et al. 2015), the critical tensile strength $f_{\mathrm{t}}$ is $2.54 \mathrm{MPa}$, and the fracture energy $G_{\mathrm{f}}$ is $138.6 \mathrm{~N} / \mathrm{m}$ (Dong et al. 2017). The shear parameters are assumed to be the same as the corresponding normal ones.

When the fracture process is simulated, a linearly increasing displacement is loaded at the two loading points until the displacement reaches $1 \mathrm{~mm}$ or the beam is completely torn apart.

\section{Results and discussion}

\subsection{Mesh dependence}

The fracture path generally depends on the mesh density and thus a fine mesh is necessary for accurate computation. However, too fine a mesh will lead to a high computational cost. Therefore, it is necessary to realize the balance between mesh density and computational efficiency.
For this purpose, three 50-mm-height concrete beam models are used to evaluate the mesh dependence. They have a void with different diameters of $1 \mathrm{~mm}, 3 \mathrm{~mm}$, and $5 \mathrm{~mm}$ at the points $(1.9 \mathrm{~mm}, 20 \mathrm{~mm}),(4.9 \mathrm{~mm}, 20 \mathrm{~mm})$, and $(7.0 \mathrm{~mm}, 20 \mathrm{~mm})$, respectively. Three different element sizes of $1.00 \mathrm{~mm}, 0.75 \mathrm{~mm}$, and $0.50 \mathrm{~mm}$ are considered in the central zones of the beams, but the element size of $2.00 \mathrm{~mm}$ is kept at the left and right sides. The fracture processes are simulated by using the ABAQUS/Explicit solver and parallel computation system with 8 Inter(R) Core (TM) i7-4790 CPUs @ 3.60 GHz. The corresponding number of nodes, numbers of triangular and quadrilateral elements, number of cohesive elements, and computing time are listed in Table 1. By comparison, it can be found that as the element length changes from $1.00 \mathrm{~mm}$ to $0.75 \mathrm{~mm}$ and $0.50 \mathrm{~mm}$, the number of nodes, the number of triangular elements, and the number of cohesive elements all increase rapidly, and the computing time also increases very quickly.

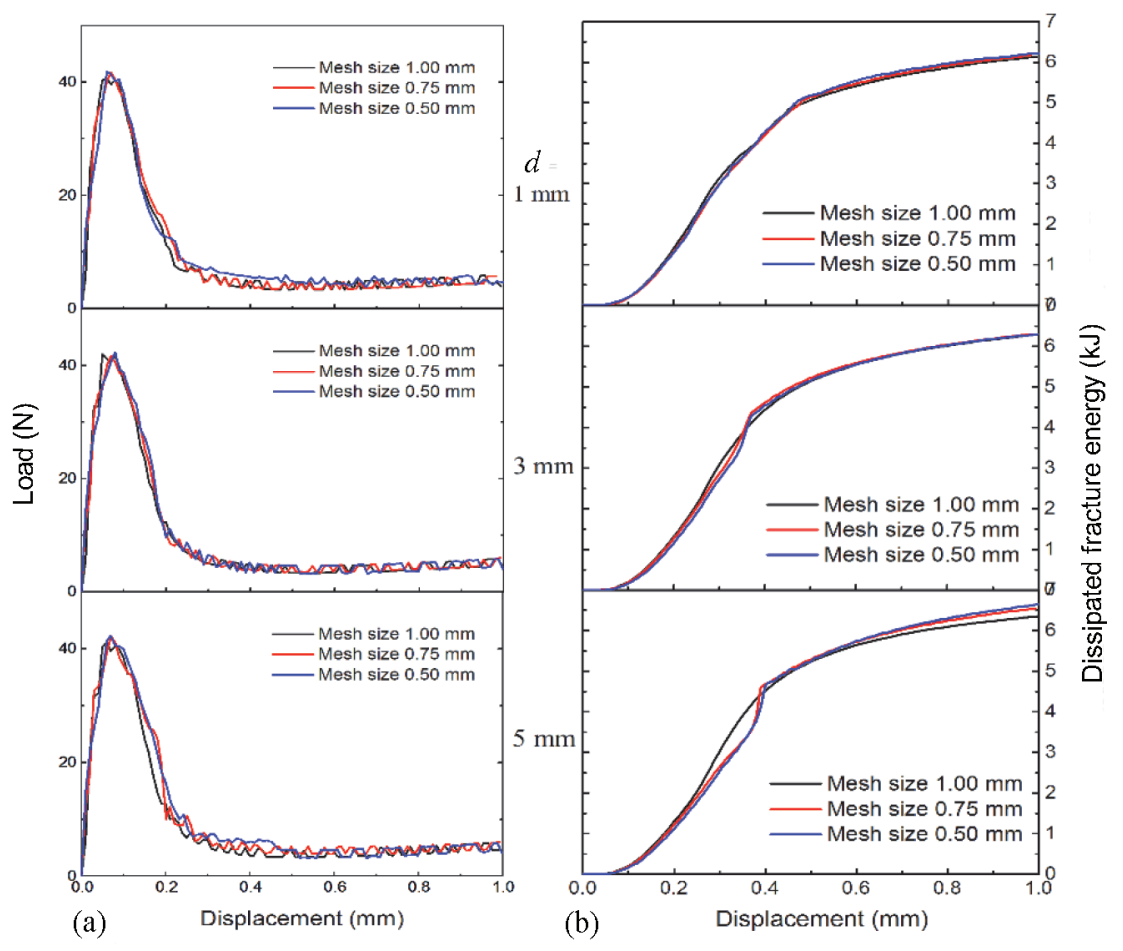

Figure 3. Load-displacement curves and dissipated fracture energy vs. displacement curves for different void and mesh sizes: (a) load-displacement; (b) dissipated fracture energy 

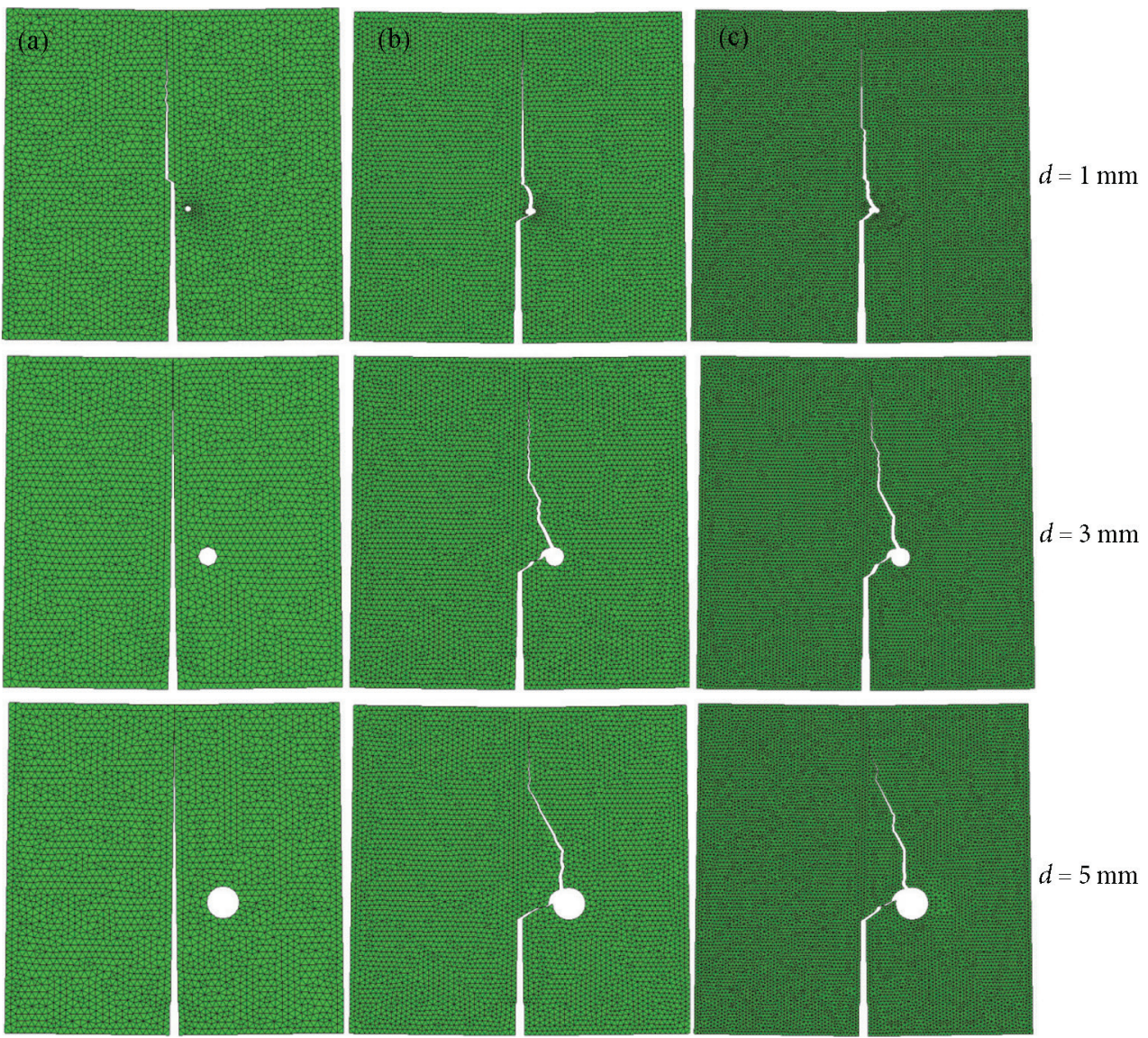

Figure 4. Crack paths for different void and mesh sizes: (a) element size of $1.00 \mathrm{~mm}$;

(b) element size of $0.75 \mathrm{~mm}$; (c) element size of $0.50 \mathrm{~mm}$

Figure 3 shows the load-displacement curves and dissipated fracture energy vs. displacement curves for different void and mesh sizes. There is a slight difference between the load-displacement curves shown in Figure 3(a), and the same is observed between the dissipated fracture energy vs. displacement curves shown in Figure 3(b). Further, the crack paths for different void and mesh sizes are compared. For cleanness, the central zones of the beams are cut out for all of the crack path pictures, as shown in Figure 4. Obviously, the crack goes through the void both in Figures 4(b) and 4(c), but it does not in Figure 4(a), and there are very similar crack paths in Figures 4(b) and 4(c). This indicates that $0.75 \mathrm{~mm}$ can be regarded as the element size for equilibrating computational accuracy and efficiency even for a void diameter of $1 \mathrm{~mm}$.

\subsection{Air-void-affected zone}

Without loss of generality, for an air void with a diameter of $3 \mathrm{~mm}$ located in the central zone of the beam with $h=50 \mathrm{~mm}$, while its $Y$ coordinate is fixed at $20 \mathrm{~mm}$, its $X$ coordinate is gradually changed from small to large in order to observe its effect on the crack path. Figure 5 shows the crack paths for the void at different $X$ coordinates. It is found that its $X$ coordinate has a critical value of about $4.9 \mathrm{~mm}$. When the $X$ coordinate is less than or equal to this critical value, the crack path will be attracted and go through the void, as shown in Figure 5(a). However, when the $X$ coordinate is larger than this critical value, the void has almost no effect on the crack path, as shown in Figure 5(b).

Accordingly, as a new concept for characterizing the effect of an air void on a fracture, the air-void-affected zone can be introduced. If we assume that the affected zone is circular, then its radius is $4.9 \mathrm{~mm}$ for the above void with a diameter of $3 \mathrm{~mm}$ and $Y$ coordinate of $20 \mathrm{~mm}$. It is possible that the affected zone size depends on the diameter and $Y$ coordinates of the void.

\subsection{Effect of air void diameter}

In this section, the $Y$ coordinate of the air void is fixed at $20 \mathrm{~mm}$, but its diameter is changed from 1 to $2,3,4$, and
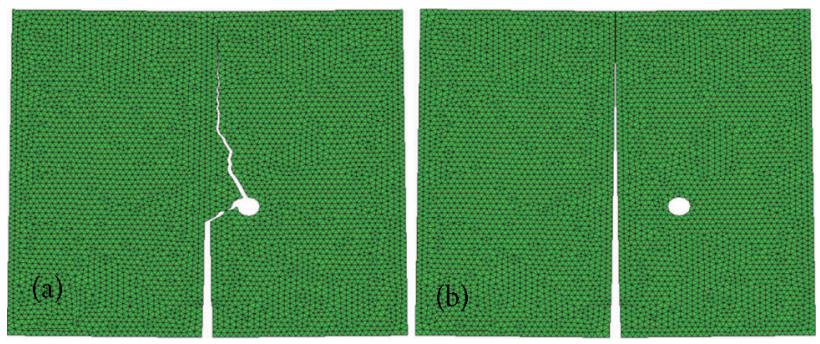

Figure 5. Crack path of concrete beams with different $X$ coordinates of the void: (a) $X=4.9 \mathrm{~mm}$; (b) $X=7.8 \mathrm{~mm}$ 


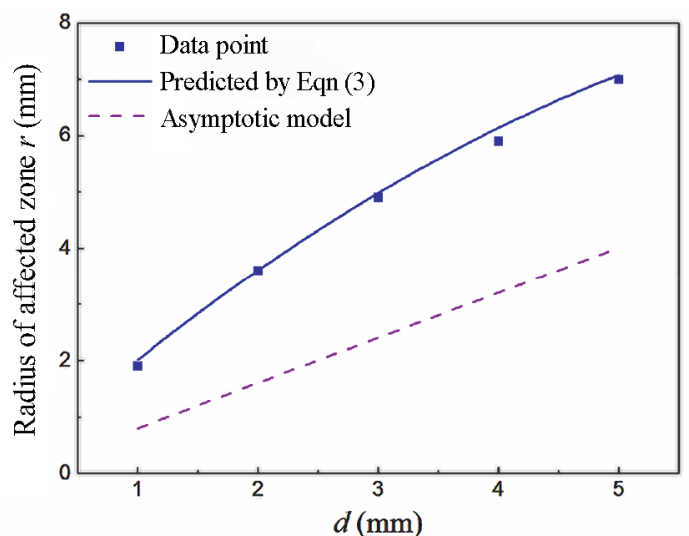

Figure 6. Variation of affected-zone radius with void diameter

$5 \mathrm{~mm}$ (Guo et al. 2016) in a concrete beam with a height of $50 \mathrm{~mm}$ to evaluate the effects of the air void diameter on the affected zone size. Figure 6 shows the variation curve of the affected-zone radius with the void diameter. It is obvious that the affected-zone radius monotonously increases with an increasing void diameter.

For a pure Mode-I fracture in a semi-infinite brittle body with a void, Valentini et al. (1999) derived an asymptotic closed-form formula for the crack path. According to this formula, for a circular void, the deflection of the crack path from the vertical axis $H$ can be expressed as a function of $l$, which is the $Y$ coordinate of the new crack tip:

$$
H(l)=\frac{\left(1-v^{2}\right) d^{2}}{8 X_{0}}\left[2-t\left(2+t-t^{2}\right)\right],
$$

where $t=\frac{Y_{0}-l}{\sqrt{X_{0}^{2}+\left(Y_{0}-l\right)^{2}}}$, and $X_{0}$ and $Y_{0}$ are the horizontal and vertical coordinates of the void center. When $H\left(Y_{0}\right)=X_{0}-\frac{d}{2}$, the crack just goes through the void. Accordingly, as the affected-zone radius, the critical value of $X_{0}$ can be obtained. It is found that the affectedzone radius depends linearly on the void diameter, namely:

$$
r=\frac{1+\sqrt{1+4\left(1-v^{2}\right)}}{4} d=0.8017 d \text {. }
$$

For comparison, this is also plotted in Figure 6 as a dashed line. Clearly, the predictions from Eqn (2) are always lower than the above numerical results. This can be attributed to the fact that the asymptotic model is only for a semi-infinite brittle body under simple tension, and is based on the assumptions of a small ratio between the void diameter and its distance to the unperturbed crack path. Misseroni et al. (2015) studied the fracture behavior of ceramics with voids experimentally and analytically. They found that when the void diameter is in close proximity to the distance from the void center to the crack path, there is an obvious difference between the asymptotic model prediction and the experimental crack path, although the prediction can still provide a good approximation of the initial crack deviation.

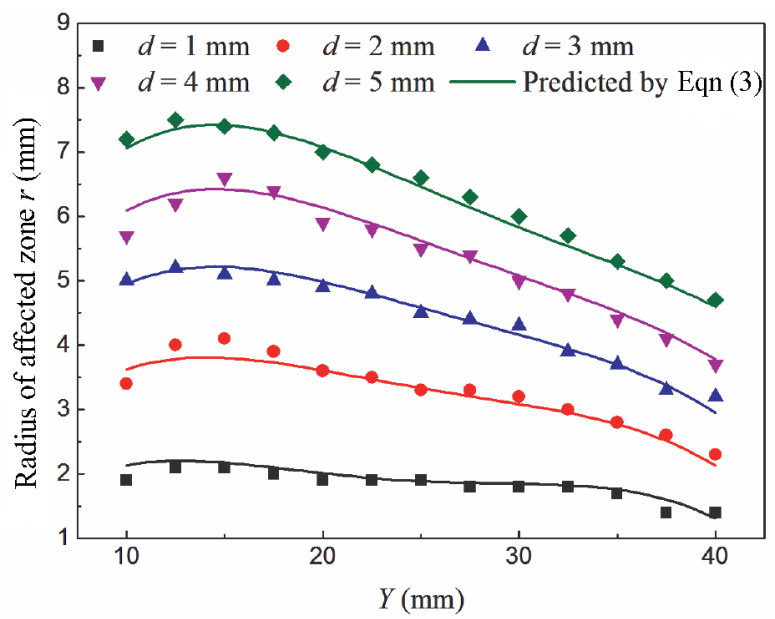

Figure 7. Radius of affected zone vs. $Y$ coordinate of void center for different void diameters

\subsection{Effect of air void location}

In this section, the effect of the air void location on a fracture is investigated by changing the $Y$ coordinate of the void center when the beam height is fixed at $50 \mathrm{~mm}$. Figure 7 shows the variation of the affected-zone radius with changes in the $Y$ coordinate for different void sizes. It is clear that there is a common tendency in the dependency of the affected-zone radius on the $Y$ coordinate of the void center. The affected-zone radius increases slightly with an increasing $Y$ coordinate in the initial stage, but decreases gradually soon afterward. As the void size increases, the range of the affected-zone radius is extended. Obviously, compared with the void size, the void location has a slight influence on the radius of the affected zone.

\subsection{Numerical fitting}

In order to exclude the effect of the beam size, the radius of the affected zone, void size, and $Y$ coordinate of the void center are all divided by the beam height. Compared with the $Y$ coordinate of the void center, the void size has a large effect on the radius of the affected zone. Accordingly, the relation of the dimensionless radius of the affected zone to the dimensionless void size and $Y$ coordinate of the void center is fitted by the following expressions, with the dimensionless void size as the dominating variable:

$$
\frac{r}{h}=f_{0}\left(\frac{Y}{h}\right)+f_{1}\left(\frac{Y}{h}\right) \times \frac{d}{h}+f_{2}\left(\frac{Y}{h}\right) \times\left(\frac{d}{h}\right)^{2},
$$

where:

$$
\begin{gathered}
f_{0}\left(\frac{Y}{h}\right)=P_{00}+P_{01} \times \frac{Y}{h}+P_{02} \times\left(\frac{Y}{h}\right)^{2}+ \\
P_{03} \times\left(\frac{Y}{h}\right)^{3}+P_{04} \times\left(\frac{Y}{h}\right)^{4} ; \\
f_{1}\left(\frac{Y}{h}\right)=P_{01}+P_{11} \times \frac{Y}{h}+P_{12} \times\left(\frac{Y}{h}\right)^{2}+P_{13} \times\left(\frac{Y}{h}\right)^{3} ;
\end{gathered}
$$


Table 2. Fitting parameters in Eqn (3)

\begin{tabular}{|crrrrrrrrrrr|}
\hline$P_{00}$ & $P_{10}$ & $P_{01}$ & $P_{20}$ & $P_{11}$ & $P_{02}$ & $P_{21}$ & $P_{12}$ & $P_{03}$ & $P_{22}$ & $P_{13}$ & $P_{04}$ \\
\hline-0.01921 & 0.5632 & 0.3760 & -0.5835 & 9.128 & -1.656 & -25.14 & -17.65 & 2.766 & 32.32 & 8.310 & -1.534 \\
\hline
\end{tabular}

$f_{2}\left(\frac{Y}{h}\right)=P_{20}+P_{21} \times \frac{Y}{h}+P_{22} \times\left(\frac{Y}{h}\right)^{2}$.

The fitting parameters $P_{i j}$ are given in Table 2 .

All of the data are redrawn in Figure 8 as blue dots, and the fitting surface is indicated in green. For comparison, the predictions from Eqn (3) are plotted in Figure 6 and Figure 7 as solid lines. It is found that there is a good consistency between the data points and the predictions. The coefficient of determination of 0.9946 indicates that the dependency of the affected-zone radius on the void diameter and location can be well characterized with Eqn (3).

In order to check the applicability of Eqn (3), some numerical simulations are conducted on a $75-\mathrm{mm}$-height beam with a void of $2,3,4$, or $5 \mathrm{~mm}$ in diameter, and a 100 -mm-height beam with a void of 3 or $5 \mathrm{~mm}$ in diameter. All voids are located at $Y=20 \mathrm{~mm}$. The obtained data are also plotted in Figure 8 as red tetrahedrons. Clearly, they can be covered by the prediction of Eqn (3).

\section{Rationality test}

In this section, two types of $2 \mathrm{D}$ beam models with a height of $50 \mathrm{~mm}$, randomly distributed circular voids, and a notch at the mid-span are built, and their FPB fracture processes are numerically simulated by using the finite element method combined with a cohesive crack model. All of the voids have the same diameter of $3 \mathrm{~mm}$ in the two Type-1 models shown in Figure 9, but the void diameter lies in a range from 1 to $5 \mathrm{~mm}$ in the Type- 2 model shown in Figure 10. Both types have the same volume fraction of $2 \%$. In order to test the legitimacy of Eqn (3), the void-affected-zone radius prediction is used to explain the choice of crack paths in these models.

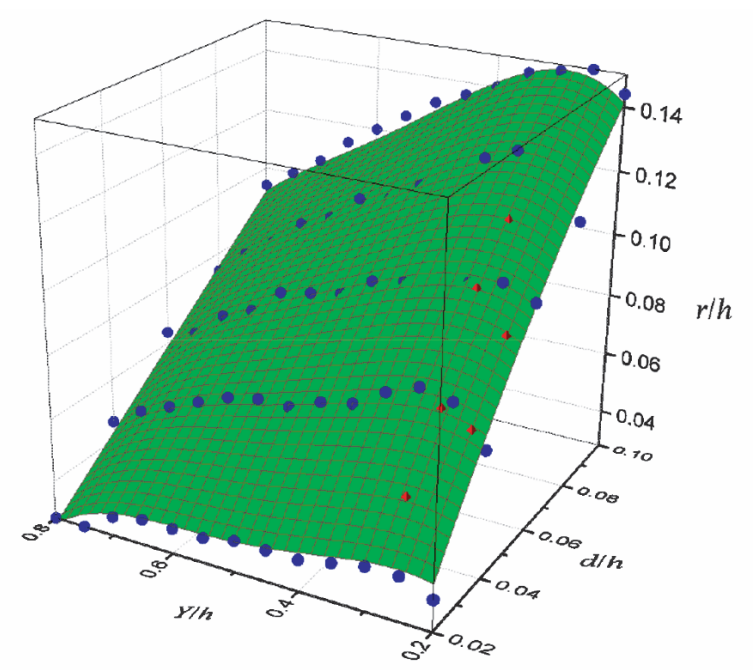

Figure 8. Variation of dimensionless radius of affected zone with dimensionless void diameter and $Y$ coordinate of void center

\subsection{Fracture in multi-void beams with the same void diameter}

Figure 9 shows the crack paths in the two Type-1 models with different void distributions, namely Distributions 1 and 2. The crack paths are marked as black lines, and the boundaries of the void-affected zones predicted by Eqn (3) are marked as colored circles.

In Figure 9(a) for Distribution 1, it is found that only one void (namely, Void A) has a considerable influence on the fracture path. The other voids have almost no influence owing to their great distances from the fracture path. When the crack enters the affected zone of Void A predicted by Eqn (3) at Site 1, the path begins to deviate to
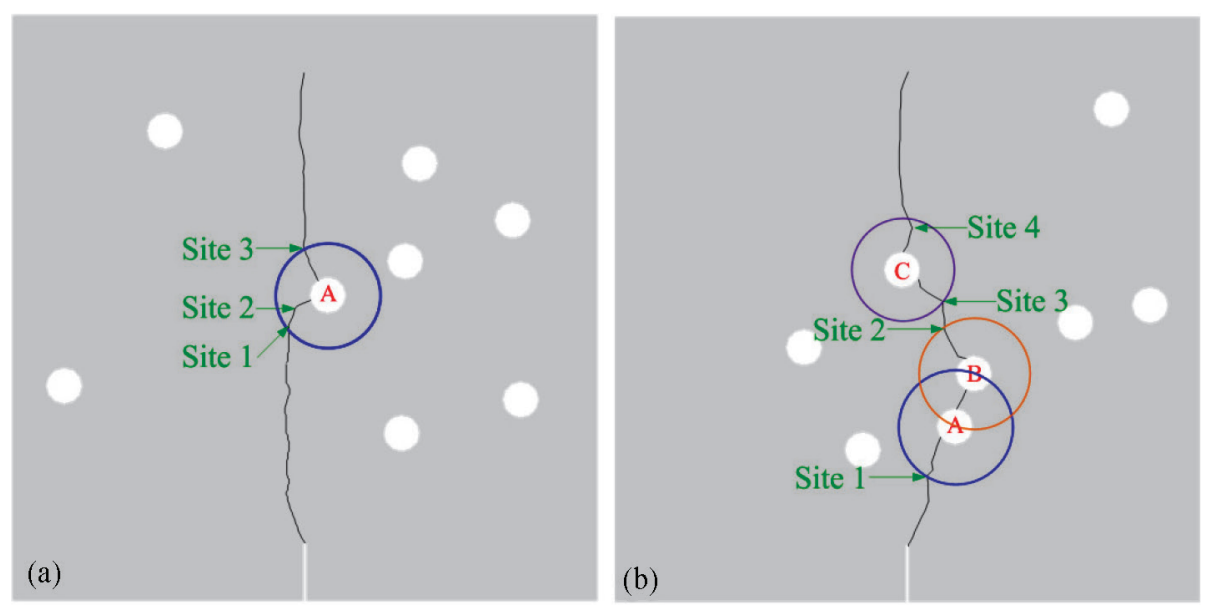

Figure 9. Crack paths in Type-1 models: (a) distribution 1; (b) distribution 2 
Void A. As the crack further comes near Void A, it is strongly attracted, so that a larger deflection occurs at Site 2. After the crack passes through Void A, the crack path seems to have a trend to return to the initial path. When the crack leaves the affected zone of Void A at Site 3 , a sharp deviation of the path occurs again. It is shown that the numerical crack path can be well explained by the void-affected-zone radius prediction from Eqn (3).

For Distribution 2, three voids affect the crack path considerably, as shown in Figure 9(b). The affected zone of Void A partly overlaps that of Void B. The crack begins to enter the affected zone of Void A at Site 1. After the crack passes through Void A, it directly moves toward Void B owing to their overlapping affected zones, and leaves the affected zone of Void B at Site 2. Then, the crack reaches the affected zone of Void C at Site 3, and leaves near Site 4. It is found that the path has an obvious deviation close to Sites 3 and 4 when the crack enters or leaves the affected zone of Void C. However, it seems that a sudden deviation occurs before the crack enters the predicted affected zone of Void A. Apparently, the prediction is accurate for Void $\mathrm{C}$ but is roughly approximate for Void A. This occurs because the interaction between voids is not considered in Eqn (3).

\subsection{Fracture in multi-void beams with different void diameters}

Figure 10 shows the crack path in the Type- 2 model with different void diameters. Compared with the Type-1 models shown in Figure 9, the Type-2 model is obviously more complex. Owing to different void diameters, there is a wide size range of the void-affected zone in this model. As a result, overlapping frequently occurs between neighboring void-affected zones such as the affected zones of Voids B and D, Voids C and D, and Voids D and E, and even the affected zone of Void C is completely covered by that of Void B.

It can be seen from Figure 10 that Void A is too distant to affect the crack path. The crack goes forward near the affected zone of Void A, and enters the affected zone of Void $\mathrm{B}$ at Site 1. An obvious deviation in the crack path occurs

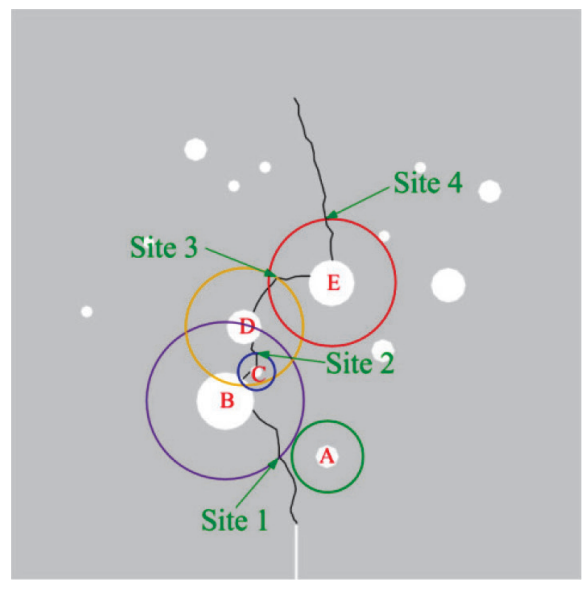

Figure 10. Crack path in Type-2 model here. Owing to overlap between the affected zones of Voids B, C, D, and E, after the crack passes through Void B, it almost directly goes through Voids C, D, and then E. The path-deviation phenomenon can also be observed when the crack leaves Voids C and D at Sites 2 and 3, respectively. However, a path perturbation seems to occur in advance when the crack leaves Void E at Site 4. This indicates that the crack path could be well explained in most cases by the void-affected-zone radius prediction from Eqn (3), although the interactions between neighboring void-affected zones are not involved.

\section{Conclusions}

The fracture behaviors of FPB concrete beams with random air voids were numerically simulated with the help of the finite element method combined with a cohesive crack model. The dependence of the void-affected-zone size on the air void size and location was carefully investigated. The following conclusions are drawn:

(1) The void-affected-zone size was determined by moving an air void horizontally until the crack path changed. Its relation to the air void size and location was given by nonlinear numerical fitting, and the effect of the void size is dominant.

(2) The affected-zone radius prediction from the fitting equation was used to explain the choice of crack paths in multi-void beams with the same or different void diameters. It was found that the prediction is accurate for an isolated affected zone but is roughly approximate for an overlapped one.

In addition, it is conceivable that the void-affectedzone size is very dependent on diverse void shapes and loading formats. This will be our direction of research in the future.

\section{Acknowledgements}

This work is supported by the National Basic Research Program of China [973 Program: 2011CB013800].

\section{References}

Barbosa, F. S.; Beaucour, A. L.; Farage, M. C. R.; Ortola, S. 2011. Image processing applied to the analysis of segregation in lightweight aggregate concretes, Construction and Building Materials 25: 3375-3381.

https://doi.org/10.1016/j.conbuildmat.2011.03.028

Başyiğit, C.; Çomak, B.; Kılınçarslan, Ş.; Serkan Üncü, İ. 2012. Assessment of concrete compressive strength by image processing technique, Construction and Building Materials 37: 526-532. https://doi.org/10.1016/j.conbuildmat.2012.07.055

Dong, W.; Wu, Z.; Zhou, X.; Dong, L.; Kastiukas, G. 2017. FPZ evolution of mixed mode fracture in concrete: Experimental and numerical, Engineering Failure Analysis 75: 54-70. https://doi.org/10.1016/j.engfailanal.2017.01.017

Dong, W.; Wu, Z.; Zhou, X.; Tan, Y. 2016. Experimental studies on void detection in concrete-filled steel tubes using ultrasound, Construction and Building Materials 128: 154-162. https://doi.org/10.1016/j.conbuildmat.2016.10.061 
Garbacz, A.; Piotrowski, T.; Courard, L.; Kwaśniewski, L. 2017. On the evaluation of interface quality in concrete repair system by means of impact-echo signal analysis, Construction and Building Materials 134: 311-323. https://doi.org/10.1016/j.conbuildmat.2016.12.064

Guo, S.; Dai, Q.; Sun, X.; Sun, Y. 2016. Ultrasonic scattering measurement of air void size distribution in hardened concrete samples, Construction and Building Materials 113: 415-422. https://doi.org/10.1016/j.conbuildmat.2016.03.051

Hassani, B.; Hinton, E. 1998. A review of homogenization and topology optimization I-homogenization theory for media with periodic structure, Computers \& Structures 69: 707-717. https://doi.org/10.1016/S0045-7949(98)00131-X

Hu, J.; Liu, P.; Wang, D.; Oeser, M.; Tan, Y. 2016. Investigation on fatigue damage of asphalt mixture with different air-voids using microstructural analysis, Construction and Building Materials 125: 936-945.

https://doi.org/10.1016/j.conbuildmat.2016.08.138

Huang, Y.; Yan, D.; Yang, Z.; Liu, G. 2016. 2D and 3D homogenization and fracture analysis of concrete based on in-situ X-ray Computed Tomography images and Monte Carlo simulations, Engineering Fracture Mechanics 163: 37-54.

https://doi.org/10.1016/j.engfracmech.2016.06.018

Mahoutian, M.; Lubell, A. S.; Bindiganavile, V. S. 2015. Effect of powdered activated carbon on the air void characteristics of concrete containing fly ash, Construction and Building Materials 80: 84-91.

https://doi.org/10.1016/j.conbuildmat.2015.01.019

Misseroni, D.; Movchan, A. B.; Movchan, N. V.; Bigoni, D. 2015. Experimental and analytical insights on fracture trajectories in brittle materials with voids, International Journal of Solids and Structures 63: 219-225.

https://doi.org/10.1016/j.ijsolstr.2015.03.001

Nambiar, E. K. K.; Ramamurthy, K. 2007. Air-void characterisation of foam concrete, Cement and Concrete Research 37: 221-230. https://doi.org/10.1016/j.cemconres.2006.10.009

Nguyen, T. T.; Bui, H. H.; Ngo, T. D.; Nguyen, G. D. 2017. Experimental and numerical investigation of influence of air-voids on the compressive behaviour of foamed concrete, Materials \& Design 130: 103-119.

https://doi.org/10.1016/j.matdes.2017.05.054

Qin, Y.; Chai, J.; Dang, F. 2013. Improved random aggregate model for numerical simulations of concrete engineering simulations of concrete engineering, Journal of Civil Engineering and Management 19: 285-295.

https://doi.org/10.3846/13923730.2012.760481

Qin, Y.; Chai, J.; Ding, W.; Dang, F.; Lei, M.; Xu, Z. 2016. A quasi real-time approach to investigating the damage and fracture process in plain concrete by X-ray tomography, Journal of Civil Engineering and Management 22: 792-799. https://doi.org/10.3846/13923730.2014.914089

Rehder, B.; Banh, K.; Neithalath, N. 2014. Fracture behavior of pervious concretes: The effects of pore structure and fibers, Engineering Fracture Mechanics 118: 1-16. https://doi.org/10.1016/j.engfracmech.2014.01.015

Ren, J.; Sun, L. 2017. Characterizing air void effect on fracture of asphalt concrete at low-temperature using discrete element method, Engineering Fracture Mechanics 170: 23-43. https:// doi.org/10.1016/j.engfracmech.2016.11.030

Ren, W.; Yang, Z.; Sharma, R.; Zhang, C.; Withers, P. J. 2015. Two-dimensional X-ray CT image based meso-scale fracture modelling of concrete, Engineering Fracture Mechanics 133: 24-39. https://doi.org/10.1016/j.engfracmech.2014.10.016
Valentini, M.; Serkov, S. K.; Bigoni, D.; Movchan, A. B. 1999. Crack propagation in a brittle elastic material with defects, Journal of Applied Mechanics 66: 79-86. https://doi.org/10.1115/1.2789172

Wang, X.; Yang, Z. J.; Yates, J. R.; Jivkov, A. P.; Zhang, C. 2015. Monte Carlo simulations of mesoscale fracture modelling of concrete with random aggregates and pores, Construction and Building Materials 75: 35-45. https://doi.org/10.1016/j.conbuildmat.2014.09.069

Wang, X.; Zhang, M.; Jivkov, A. P. 2016. Computational technology for analysis of 3D meso-structure effects on damage and failure of concrete, International Journal of Solids and Structures 80: 310-333.

https://doi.org/10.1016/j.ijsolstr.2015.11.018

Xie, Y.; Corr, D. J.; Jin, F.; Zhou, H.; Shah, S. P. 2015. Experimental study of the interfacial transition zone (ITZ) of model rockfilled concrete (RFC), Cement and Concrete Composites 55: 223-231. https://doi.org/10.1016/j.cemconcomp.2014.09.002

$\mathrm{Xu}, \mathrm{Y}$.; Chen, S. 2016. A method for modeling the damage behavior of concrete with a three-phase mesostructure. Construction and Building Materials 102: 26-38.

https://doi.org/10.1016/j.conbuildmat.2015.10.151

Yang, Z. J.; Su, X. T.; Chen, J. F.; Liu, G. H. 2009. Monte Carlo simulation of complex cohesive fracture in random heterogeneous quasi-brittle materials, International Journal of Solids and Structures 46: 3222-3234.

https://doi.org/10.1016/j.ijsolstr.2009.04.013

Yin, A.; Yang, X.; Gao, H.; Zhu, H. 2012. Tensile fracture simulation of random heterogeneous asphalt mixture with cohesive crack model, Engineering Fracture Mechanics 92: 40-55. https://doi.org/10.1016/j.engfracmech.2012.05.016

Yin, A.; Yang, X.; Zeng, G.; Gao, H. 2014. Fracture simulation of pre-cracked heterogeneous asphalt mixture beam with movable three-point bending load, Construction and Building $M a-$ terials 65: 232-242. https://doi.org/10.1016/j.conbuildmat.2014.04.119

Yin, A.; Yang, X.; Zeng, G.; Gao, H. 2015. Experimental and numerical investigation of fracture behavior of asphalt mixture under direct shear loading, Construction and Building Materials 86: $21-32$.

https://doi.org/10.1016/j.conbuildmat.2015.03.099

Zhang, C.; Yang, X.; Gao, H.; Zhu, H. 2016. Heterogeneous fracture simulation of three-point bending plain-concrete beam with double notches, Acta Mechanica Solida Sinica 29: 232244. https://doi.org/10.1016/S0894-9166(16)30158-6 